\title{
Erratum to: An overview of infectious bursal disease
}

\author{
Hebata Allah Mahgoub • Michael Bailey • \\ Pete Kaiser
}

Published online: 14 October 2012

(C) Springer-Verlag Wien 2012

\section{Erratum to: Arch Virol \\ DOI 10.1007/s00705-012-1377-9}

In the original publication of the article, the co-authors Michael Bailey and Pete Kaiser were inadvertently omitted.

In addition, the authors would like to include the below "Acknowledgments" and remove the cited reference [54] in the legends of Figs. 2, 3 and 4.

Acknowledgments This work was funded by a $\mathrm{PhD}$ scholarship to Dr Mahgoub from the Egyptian Ministry of Higher Education, administered through the Cultural Centre and Educational Bureau, Embassy of the Arab Republic of Egypt, London and supported by the Biotechnology and Biological Sciences Research Council through an Institute Strategic Programme Grant to the IAH. We thank Professor Nicolas Eterradossi, AFFSA, France for the kind gift of the vvIBDV strain UK661. We also thank the staff of the Experimental Animal House, IAH, for their assistance with the challenge experiments.

The online version of the original article can be found under doi:10.1007/s00705-012-1377-9.

H. A. Mahgoub ( $₫)$

Faculty of Veterinary Medicine, Mansoura University,

Mansoura, Egypt

e-mail: heba.a.mahgoub@gmail.com

H. A. Mahgoub · P. Kaiser

Institute for Animal Health, Compton,

Berkshire RG20 7NN, UK

\section{Bailey}

Infection and Immunity, School of Veterinary Science,

University of Bristol, Langford, Somerset, UK

Present Address:

P. Kaiser

The Roslin Institute and R(D)SVS, University of Edinburgh,

Easter Bush, Midlothian EH25 9RG, UK 